\title{
Association of Lifestyle and Food Consumption with Bone Mineral Density among People Aged 50 Years and Above Attending the Hospitals of Kathmandu, Nepal
}

\author{
Narendra Kumar Chaudhary, ${ }^{1}$ Mukti Nath Timilsena, ${ }^{2}$ Dev Ram Sunuwar $\left(\mathbb{D},{ }^{3}\right.$ \\ Pranil Man Singh Pradhan $\mathbb{D}^{4},{ }^{4}$ and Raj Kumar Sangroula ${ }^{5}$ \\ ${ }^{1}$ Department of Radiology, Nepal Orthopaedic Hospital, Kathmandu, Nepal \\ ${ }^{2}$ Department of Orthopaedic Surgery, Nepal Orthopaedic Hospital, Kathmandu, Nepal \\ ${ }^{3}$ Department of Nutrition and Dietetics, Armed Police Force Hospital, Kathmandu, Nepal \\ ${ }^{4}$ Department of Community Medicine and Public Health, Institute of Medicine, Tribhuvan University, Nepal \\ ${ }^{5}$ Department of Nutrition and Dietetics, College of Applied Food and Dairy Technology, Kathmandu, Purbanchal University, Nepal
}

Correspondence should be addressed to Dev Ram Sunuwar; devramsunuwar@gmail.com

Received 18 December 2018; Accepted 8 May 2019; Published 22 May 2019

Academic Editor: Manuel Diaz Curiel

Copyright (C) 2019 Narendra Kumar Chaudhary et al. This is an open access article distributed under the Creative Commons Attribution License, which permits unrestricted use, distribution, and reproduction in any medium, provided the original work is properly cited.

\begin{abstract}
Background. Bone mineral density (BMD) is the measure of the minerals, mostly calcium and phosphorous, contained in certain volume of bone to diagnose osteoporosis. The aim of the study was to find out the association of lifestyle and food consumption with BMD. Methods. An analytical cross-sectional study was conducted among 169 people of age 50 years and above who underwent Dual Energy X-Ray Absorptiometry (DEXA or DXA) scan in the hospitals of Kathmandu valley of Nepal. Food frequency questionnaire and 24-hour recall methods were followed. The DXA reports of the participants were observed to identify osteoporosis. Chisquare test, independent sample t-test, and binary logistic regression were applied to explore the association of BMD with different variables. Result. The prevalence of osteoporosis, osteopenia, and normal BMD was $37.3 \%$, 38.5\%, and $24.2 \%$, respectively. The prevalence of osteoporosis increased with sex and age (AOR 3.339, CI: 1.240-8.995, p-value 0.017; AOR 3.756, CI: 1.745-8.085, p-value 0.001), respectively. Higher BMI was associated with lower odds of osteoporosis (AOR 0.428, CI: 0.209-0.877, p-value 0.020). Smoking had bad effect on the health of bone (AOR 3.848, CI: 1.179-12.558, p-value 0.026). Daily dietary calcium intake had negative association with osteoporosis with the p-value of 0.003 ; however, the daily consumption of vitamin $\mathrm{D}$ rich food had no association with osteoporosis. Conclusion. High prevalence of osteoporosis and osteopenia was found in older people. Osteoporosis was found to be significantly associated with sex, age, lower BMI, smoking habit, and daily calcium consumption. Further research can be conducted by making the relationship of calcium consumption with the numerical T-value of scanned body parts.
\end{abstract}

\section{Introduction}

Bone density usually refers to the degree to which a radiation beam is attenuated by a bone, as judged from a twodimensional projection image (areal bone density) in clinical practice and science [1]. The purpose of bone densitometry is to diagnose the osteoporosis, to evaluate fracture risk, and to determine whether treatment is required or not. There is a statistical association between poor bone density and higher probability of fracture [2]. Poor bone mass leads to the fracture with low energy trauma [3].

Osteoporosis is a progressive skeletal disease. It is characterized by low bone mass and microarchitectural deterioration of bone tissue structure, with a consequent increase in bone fragility and susceptibility to fractures [4]. It is a silent disease that appears later in life. The prevalence of osteoporosis is very high worldwide. One in two women and one in five men aged 50 years or over will suffer an osteoporotic 
fracture [5]. About $10 \%$ of US adults of age 50 years and older had osteoporosis and $43.9 \%$ had low bone mass at the femoral neck or lumbar spine in NHANES 2005-2010 census study [6]. The prevalence of osteoporosis was $50 \%$ and that of osteopenia was $36 \%$ in the persons above 50 years old in the hospitalized setting, a tertiary care centre of South India [7]. It has been found that $90 \%$ of the postmenopausal women had subnormal T-scores in the Moradabad of India [8]. Very few studies about osteoporosis are found in the context of Nepal. The prevalence of osteoporosis among the middle aged women in Chitwan district of Nepal is $26.2 \%$, osteopenia is $39.3 \%$, and normal BMD is $34.4 \%$ at wrist site [9]. Another study indicates that $15 \%$ of postmenopausal women had osteoporosis and $21 \%$ had osteopenia in the Gandaki Medical College Teaching Hospital, Pokhara of Nepal [10].

Osteoporosis may cause the patients to be bedridden with back pain, loss of height, kyphosis, pneumonia, and pulmonary thromboembolism. The treatment costs are the most expensive after diabetes, hyperlipidaemia, hypertension, and heart diseases [11]. Lifestyle and dietary behavior are important factors for the health of bone [12]. Deficiency of calcium and vitamin $\mathrm{D}$ contributes to alterations of bone remodeling and bone integrity [13]. Dietary calcium has significant positive association with higher BMD at all sites of our body [14].

This study has attempted to explore the association of lifestyle and food consumption with BMD among people of age 50 years and above in Kathmandu of Nepal by analyzing the DXA report. DXA is considered as the gold standard method for bone densitometry. The precision error of current DXA systems is $1.0 \%$ for whole body, $\sim 0.5-1 \%$ for the spine, and $2.0-5.0 \%$ for the femoral neck, depending on anatomic site analyzed [15]. This technology is recently brought in Nepal and available in very few hospitals of Kathmandu. Therefore there is a lack of studies about BMD through DXA report. Besides these, the cost of DXA scan is high, so this investigation is not normally preferred for patients with low economic background. That is why there is no authentic data for the prevalence of osteoporosis in Nepal as well.

\section{Materials and Methods}

The study was a cross-sectional analytical study conducted over a duration of six months from October 2017 to March 2018. This study was registered and approved by the Research and Institutional Review Committee (IRC) of Nepal Medical College Teaching Hospital (NMCTH) (Reference number: 33-074/075). The respondents of the study were the patients of age 50 years and above who had undergone Dual Energy XRay Absorptiometry (DXA). Written informed consent was taken from the participants. The study was conducted at the four super-speciality hospitals of Kathmandu where DXA facility was available. As this study was hospital based, we used the consecutive sampling method until the sample size was met. The patients who were seriously ill, fractured case, and having DXA report of sites other than lumbosacral spine and both femurs were excluded from the study.
The sample size was determined by using a single proportional formula using the prevalence rate of osteoporosis in India. The prevalence of osteoporosis in patients aged 50 years and above was $50 \%$ according to studies from South India [7]. We determined sample size by taking $95 \%$ confidence interval (CI) and $8 \%$ margin of error (d). Hence, with $13 \%$ nonresponse rate, the total sample size would be 169. Data collection was done through the observation of DXA reports of patients. All the hospitals under study had the same manufacturer machine, GE Lunar Prodigy. Before conducting the DXA scan, the machine was calibrated by the concerned operators for the accuracy of the diagnosis. Food habit and lifestyle factors were explored through 24hour dietary recall and food frequency questionnaire survey. For this, a questionnaire was developed and pilot study was done.

Data were entered into EpiData version 3.2 and analyzed by using SPSS 20. The prevalence of osteoporosis in older people was estimated through descriptive statistical tools using WHO criteria for osteoporosis (normal BMD if T-score is equal to or above -1 S.D., osteopenia if T-score ranges between -1 S.D. and -2.5 S.D, and osteoporosis if T-score is equal to or below -2.5 S.D). Subjects were classified as having osteoporosis if at least one of the two measurements (lumbar spine or femur) indicated osteoporosis and as having osteopenia if at least one measurement indicated osteopenia, but none indicated osteoporosis. The pattern of consumption of calcium rich food was explored qualitatively. Sufficient intake was estimated through food habit pattern. The categorical independent lifestyle related variables such as smoking, exercise, and alcohol consumption were explored. Through the 24-hour recall, dietary daily calcium intake was calculated manually with the help of food composition table 2012 of Nepal [16]. Similarly daily dietary vitamin D consumption was calculated by using food composition table 2017 of India [17]. Measurement list for the nutritive value (calcium and vitamin D) per household was prepared for the ease of calculation. The household measurement of simple and traditional tea glass of $130 \mathrm{ml}$ was displayed while interviewing respondents for approximate value, as per the principles and guidelines made by the Dietary Department of Tribhuvan University Teaching Hospital (TUTH), Kathmandu, Nepal, and also the guidelines of ASTHA Nepal. Chi-square test and independent t-test were applied to find out the association of different variables with BMD. BMD was further categorized as osteoporosis and no osteoporosis. No osteoporosis was considered both for osteopenia and normal BMD. All associations with probability values less than $0.05(\mathrm{p}<0.05)$ have been considered statistically significant. Binary logistic regression analysis was used for the multivariate analysis of $\mathrm{p}$-value less than $0.05(\mathrm{p}<0.05)$.

\section{Results}

The aim of the study was to find out the association of lifestyle and food consumption with bone mineral density among people of age 50 years and above attending the hospitals of Kathmandu. Most of the patients were 60 years old and above and females (Table 1). 
TABLE 1: Characteristics of respondents $(n=169)$.

\begin{tabular}{|c|c|}
\hline Variables & Mean \pm S.D. \\
\hline Age (in years) & $63.46 \pm 9.784$ \\
\hline Height & $152.5760 \pm 7.32034$ \\
\hline Weight & $60.0994 \pm 11.59607$ \\
\hline BMI & $25.7784 \pm 4.48414$ \\
\hline Daily calcium intake (in mg) & $520.4488 \pm 296.97648$ \\
\hline Daily dietary vitamin D intake (in IU) & $578.6688 \pm 435.53989$ \\
\hline \multicolumn{2}{|l|}{ BMD value (T-score in S.D.) } \\
\hline LS Spine-AP & $-1.6976 \pm 1.66812$ \\
\hline Right Femur-AP & $-1.2284 \pm 1.38104$ \\
\hline Left Femur-AP & $-1.2538 \pm 1.37720$ \\
\hline Variables & Frequency $(\%)$ \\
\hline \multicolumn{2}{|l|}{ Sex } \\
\hline Male & $38(22.5 \%)$ \\
\hline Female & $131(77.5 \%)$ \\
\hline \multicolumn{2}{|l|}{ Age } \\
\hline 50 to 59 Years & $67(39.6 \%)$ \\
\hline 60 years and above & $102(60.4 \%)$ \\
\hline \multicolumn{2}{|l|}{$B M I$} \\
\hline Underweight & $0(0 \%)$ \\
\hline Normal & $71(42 \%)$ \\
\hline Overweight & $98(58 \%)$ \\
\hline \multicolumn{2}{|l|}{ Smoking habit } \\
\hline Yes & $21(12.4 \%)$ \\
\hline No & $148(87.6 \%)$ \\
\hline \multicolumn{2}{|l|}{ Alcohol intake } \\
\hline Yes & $53(31.4 \%)$ \\
\hline No & $116(68.6 \%)$ \\
\hline \multicolumn{2}{|l|}{ Daily Tea intake } \\
\hline Yes & $149(88.2 \%)$ \\
\hline No & $20(11.8 \%)$ \\
\hline \multicolumn{2}{|l|}{ Daily exercise } \\
\hline Yes & $67(39.6 \%)$ \\
\hline No & $102(60.4 \%)$ \\
\hline
\end{tabular}

Most of the patients were nonvegetarian. About $90 \%$ of the participants had less calcium intake than DRI (Table 2).

The prevalence of osteoporosis, osteopenia, and normal BMD was measured both at lumbosacral spine and femoral neck. Overall 24.2\% had normal BMD, 38.5\% had osteopenia, and $37.3 \%$ had osteoporosis (Table 3 ).

The incidence of osteoporosis was more in females than in males. Similarly osteoporosis was positively associated with age and smoking while it was negatively associated with BMI; however it was not associated with daily exercise and daily tea consumption (Table 4).

The daily calcium intake had good effect on the health of bone while daily dietary vitamin $\mathrm{D}$ intake had no association with osteoporosis (Table 5).
TABLE 2: Dietary habit of respondents ( $\mathrm{n}=169)$.

\begin{tabular}{lc}
\hline Variables & Frequency (\%) \\
\hline Food Habit & \\
$\quad$ Vegetarian & $22(13 \%)$ \\
Non-vegetarian & $147(87 \%)$ \\
Milk and milk products consumption & \\
Daily & $109(64.5 \%)$ \\
Once a week & $60(35.5 \%)$ \\
Green Vegetables consumption & \\
Daily & $136(80.5 \%)$ \\
Once in week & $33(19.5 \%)$ \\
Fish consumption & \\
Never & $22(13 \%)$ \\
Daily & $20(11.8 \%)$ \\
Once in week & $127(75.1 \%)$ \\
Daily calcium intake & \\
$<500$ mg & $92(54.44 \%)$ \\
500 to 999 mg & $71(42.01 \%)$ \\
$\geq 1000$ mg & $6(3.55 \%)$ \\
\hline
\end{tabular}

\section{Discussion}

4.1. Prevalence of Osteoporosis. Prevalence of osteoporosis increased with age and it was more in females $[18,19]$. Prevalence of the osteoporosis was found to be $37.3 \%$ in people of age 50 years and above, which is less than that in the findings of the study done in India [7]. It may be because of application of quantitative ultrasound (QUS) in those studies. QUS screening for osteoporosis is appropriate for younger perimenopausal woman due to its mode of action and, hence, not appropriate for older people as the bone of older patients is too compact to allow penetration by ultrasound [18]. Different cut-off values for diagnosis are used by different QUS devices that underestimate the true prevalence of osteoporosis, which indicates the poorer precision compared to DXA [19]. Another study also indicated higher prevalence of osteoporosis among the postmenopausal women from QUS than DXA methods [20]. The prevalence of osteoporosis was $9 \%$ in females of age group 50-60 years while there was no osteoporosis in males of the same age group in Pokhara by Peripheral Radial Densitometry [10]. Similarly, the prevalence of osteoporosis was $26.2 \%$ in premenopausal and postmenopausal women in Chitwan district of Nepal through the quantitative ultrasound technology at wrist joints [9]. However, peripheral skeletal sites are not clinically useful to monitor the changes in BMD for the diagnosis of osteoporosis [21].

4.2. Lifestyle and BMD. There are many lifestyle factors that affect BMD. Participants with normal BMI had high prevalence of occurring osteoporosis than people who were overweight or obese. The higher body weight makes a huge mechanical load on the bone, hence increasing the bone mass to accommodate this load, and for this the body fat acts to exert a protective factor for fracture [22]. However 
TABLe 3: Prevalence of osteoporosis $(n=169)$.

\begin{tabular}{|c|c|c|c|c|}
\hline Respondents & Normal & Osteopenia & Osteoporosis & Total \\
\hline \multicolumn{5}{|l|}{ Age } \\
\hline 50 to 59 years & $23(34.3 \%)$ & $31(46.3 \%)$ & $13(19.4 \%)$ & $67(39.6 \%)$ \\
\hline 60 years and above & $18(17.6 \%)$ & $34(33.33 \%)$ & $50(49.1 \%)$ & $102(60.4 \%)$ \\
\hline \multicolumn{5}{|l|}{ Sex } \\
\hline Male & $12(31.6 \%)$ & $17(44.7 \%)$ & $9(23.7 \%)$ & $38(22.5 \%)$ \\
\hline Female & $29(22.1 \%)$ & $48(36.6 \%)$ & $54(41.2 \%)$ & $131(77.5 \%)$ \\
\hline Total & $41(24.2 \%)$ & $65(38.5 \%)$ & $63(37.3 \%)$ & $169(100 \%)$ \\
\hline
\end{tabular}

TABLE 4: Association of different variables with BMD.

\begin{tabular}{|c|c|c|c|c|c|c|}
\hline \multirow{2}{*}{ Variables } & \multirow{2}{*}{ No osteoporosis } & \multirow{2}{*}{ Osteoporosis } & \multicolumn{2}{|c|}{ Bivariate analysis } & \multicolumn{2}{|c|}{ Multivariate analysis } \\
\hline & & & $\mathrm{p}$-value & COR(95\%CI) & $\mathrm{p}$-value & $\operatorname{AOR}(95 \% \mathrm{CI})$ \\
\hline \multicolumn{7}{|l|}{ Sex } \\
\hline Male & 29 & 9 & & Ref & & Ref \\
\hline Female & 77 & 54 & $0.049 *$ & $2.260(0.990-5.516)$ & $0.017 * *$ & $3.339(1.240-8.995)$ \\
\hline \multicolumn{7}{|l|}{ Age } \\
\hline $50-59$ years & 54 & 13 & & Ref & & Ref \\
\hline 60 years and above & 52 & 50 & $<0.001 *$ & $3.994(1.946-8.200)$ & $0.001 * *$ & $3.756(1.745-8.085)$ \\
\hline \multicolumn{7}{|l|}{$B M I$} \\
\hline Normal & 34 & 37 & $0.001 *$ & $3(1.6-5.7)$ & $0.020 * *$ & $2.339(1.141-4.795)$ \\
\hline Overweight/obese & 72 & 26 & & Ref & & Ref \\
\hline \multicolumn{7}{|l|}{ Smoking } \\
\hline Yes & 9 & 12 & $0.04 *$ & $2.534(1.002-6.417)$ & $0.026 * *$ & $3.848(1.179-12.558)$ \\
\hline No & 97 & 51 & & Ref & & Ref \\
\hline \multicolumn{7}{|l|}{ Alcohol consumption } \\
\hline Yes & 40 & 13 & $0.021 *$ & $0.429(0.208-0.886)$ & 0.143 & $0.525(0.221-1.244)$ \\
\hline No & 66 & 50 & & Ref & & Ref \\
\hline \multicolumn{7}{|l|}{ Daily exercise } \\
\hline Yes & 48 & 19 & 0.052 & $0.522(0.270-1.010)$ & - & - \\
\hline No & 58 & 44 & & Ref & & \\
\hline \multicolumn{7}{|l|}{ Tea consumption } \\
\hline Yes & 95 & 54 & 0.447 & $0.659(0.271-1.782)$ & & \\
\hline No & 11 & 9 & & Ref & - & - \\
\hline
\end{tabular}

* denotes significant variables, P-value $<0.05$, for bivariate analysis.

$* *$ denotes significant variables, $\mathrm{P}$-value $<0.05$, for multivariate analysis.

COR: crude odds ratio.

AOR: adjusted odds ratio.

Ref: reference category.

TABLE 5: Dietary association with BMD.

\begin{tabular}{lccc}
\hline Result & Frequency & Mean \pm SD & P-Value \\
\hline Calcium consumption (in $m g$ ) & & & \\
No osteoporosis & 106 & $572.32 \pm 332.52$ & $0.003 *$ \\
Osteoporosis & 63 & $433.17 \pm 198.43$ & \\
Vitamin D intake (in IU) & & $574.19 \pm 314.82$ & \\
No osteoporosis & 106 & $586.19 \pm 588.19$ & 0.863 \\
Osteoporosis & 63 & & \\
\hline
\end{tabular}

* denotes significant variable, $\mathrm{P}$-Value $<0.05$, for independent sample t-test.

it is important to remember that not all types of fat are beneficial for bone mass. Low BMI individuals lose more bone compared to those with higher BMI individuals [23]. Similarly, the smokers had three times more probability of having osteoporosis than nonsmokers which is supported by different studies [24, 25]. Smoking decreases the calcium absorption [26]. Hence it decreases the bone mineral density and increases the risk of sustaining the fractures or tendon injury [27]. Alcohol consumption had protective effect on bone health from bivariate analysis. Participants who consumed moderate level of alcohol, that is, 0.5 to 1 drinks (15 $\mathrm{ml}$ to $30 \mathrm{ml}$ ) per day, had a lower risk of hip fracture [28]. However, high consumption of alcohol increases the calcium lost in urine which reduces the bone mass [29].

Several studies revealed that osteoporosis was not associated with daily exercise $[30,31]$ which was also found 
in this study. Daily tea consumption did not show any beneficial effect on the improvement of BMD. However, consumption of tea has good effect on bone mineral density $[32,33]$. This may be due to the difference in frequency and concentration of consumption of tea. Studies have shown that mean consumption of milk tea was five glasses with coffee per day while in the present study most of the participants consumed two glasses of black tea. The caffeine concentration in tea is generally less than $50 \%$ of the concentration found in coffee [34], and the bioactive components of tea support the osteoblastic activities and suppress the osteoclastic activities [35].

4.3. BMD with Calcium Consumption and Vitamin D Intake. The mean intake of calcium consumption was found to be 520 mg which is similar to the study done in South India [36]. It was found that osteoporosis was negatively associated with daily calcium intake which has been supported by different studies $[14,37,38]$. There was no association of vitamin D intake from food with osteoporosis. This finding has been supported by another study [39]. This type of finding may be due to the fact that $50-90 \%$ of total vitamin D requirement can be fulfilled by sun exposure, and only $5-10 \%$ of total vitamin D can be achieved from food [11].

This study has several limitations. Sample size was less due to unavailability of patients as DXA facility is a new and expensive technology in the context of Kathmandu, Nepal. Similarly, the food composition table 2012 of Nepal does not include calcium value of many foods like momo (a type of South Asian dumpling) which is mostly consumed in Kathmandu.

\section{Conclusion}

About three-fourths of people of age 50 years and above had lower BMD suffering from the osteopenia and osteoporosis. The high prevalence of osteopenia and osteoporosis is positively associated with the daily low calcium intake from foods, lower BMI, smoking habit, sex especially female, and increasing age after 50 years. Therefore older people should be prioritized for calcium rich food and supplementation for the prevention of osteoporosis. As this study could not make any relationship of the numerical T-score value with the amount of calcium intake, further study can be conducted from this perspective.

\section{Data Availability}

The data used to support the findings of this study are available from the corresponding author upon request.

\section{Conflicts of Interest}

The authors declare that they have no conflicts of interest.

\section{Authors' Contributions}

Narendra Kumar Chaudhary was a principal investigator. He participated in data collection, analysis, and management and manuscript drafting and critical revision. Raj Kumar Sangroula was involved in the formulation of concept and design of the study, statistical analysis and interpretation of results, preparation of manuscript, and overall supervision of the research. Mukti Nath Timilsena was involved in the review of human physiology from clinical aspect, BMD technology, and rewriting, in addition to playing a role as cosupervisor. Dev Ram Sunuwar actively assisted in data analysis, management, and interpretation and manuscript writing. Pranil Man Singh Pradhan assisted in manuscript writing and overall critical review.

\section{Acknowledgments}

We are grateful to Professor Dr. Kalpana Tiwari, Director of Research and Planning, College of Applied Food and Dairy Technology, Purbanchal University, whose cooperation on this research is significant. We would also like to acknowledge Ms. Nani Shova Shakya, Senior Dietician, Tribhuvan University Teaching Hospital, for her support in the estimation of serving size, household measurement, and, of course, calculation of nutritive value of different Nepalese foods.

\section{Supplementary Materials}

Supplementary 1. S1 Dataset.

Supplementary 2. S2 STROBE checklist.

\section{References}

[1] F. Rauch and E. Schoenau, "Skeletal development in premature infants: a review of bone physiology beyond nutritional aspects," Archives of Disease in Childhood - Fetal and Neonatal Edition, vol. 86, no. 2, pp. 82F-85F, 2002.

[2] N. K. Multani, H. Kaur, and H. K. Chahal, "Impact of sporting activities on bone mineral density," Journal of Exercise Science and Physiotherapy, vol. 7, no. 2, pp. 103-109, 2011.

[3] K. Akesson, New Approaches to Pharmacological Treatment of Osteoporosis, World Health Organisation, 2003.

[4] I. F. Christogiannis, I. Laskarina, M. Evanthia, and F. M. P. J. P. Andreas, "Osteoporosis and exercise," EEXOT, vol. 64, no. 2, pp. 85-92, 2013.

[5] International Osteoporosis Foundation (IOF), Annual Report, 2016, https://www.iofbonehealth.org/sites/default/files/PDFs/ Annual-Report-2016-WEB.pdf.

[6] N. C. Wright, A. C. Looker, K. G. Saag et al., "The recent prevalence of osteoporosis and low bone mass in the United States based on bone mineral density at the femoral neck or lumbar spine," Journal of Bone and Mineral Research, vol. 29, no. 11, pp. 2520-2526, 2014.

[7] A. Hemalata, R. M. Mani, and V. K. Sreekala, “The prevalence of osteoporosis and osteopenia in persons above 50 years attending a tertiary care hospital in South India," Journal of Medical Science and Clinical Research, vol. 4, no. 12, pp. 1445814462, 2016.

[8] R. Najam and N. Huda, "Assessment of osteoporosis in post menopausal women: a clinical study," Nepal Journal of Obstetrics \& Gynaecology, vol. 6, no. 2, pp. 11-13, 2011. 
[9] K. S. Dhakal, S. Dhakal, and B. Aryal, "Prevalence of osteoporosis among middle aged women in Chitwan District of Nepal," International Journal of Pharmaceutical \& Biological Archives, vol. 3, no. 4, pp. 779-782, 2012.

[10] C. Pandit, B. R. Neupane, R. T. Gurung, T. K. Gurung, and R. B. K. Shrestha, "Evaluation of postmenopausal women and men aged above 50 for risk factors associated with osteoporosis," Journal of Gandaki Medical College, vol. 8, no. 2, 2015.

[11] J. Geddam, Determinants and Their Correlation with Bone Parameters of Men and Women with Osteoporosis Hip Fractures Case Control Study, Osteoporos Andhra Pradesh, India.

[12] A. C. Kawalkar, "A comprehensive review on osteoporosis," Journal of Trauma and Orthopaedic Surgery, vol. 9, no. 4, pp. 3-12, 2014.

[13] M. Srivastava and C. Deal, "Osteoporosis in elderly: prevention and treatment," Clinics in Geriatric Medicine, vol. 18, no. 3, pp. 529-555, 2002.

[14] C. Pongchaiyakul, V. Kosulwat, S. Charoenkiatkul, L. Chailurkit, N. Rojroongwasinkul, and R. Rajatanavin, "The association of dietary calcium, bone mineral density and biochemical bone turnover markers in rural Thai women," Journal of the Medical Association of Thailand, vol. 91, no. 3, pp. 295-302, 2008.

[15] M. K. Zack, Reliability and Validity of Body Composition and Bone Mineral Density Measurements by DXA, Virginia Tech, 2003, https://vtechworks.lib.vt.edu/handle/10919/31741.

[16] "Food composition tabel For Nepal," Tech. Rep., Department of Food Technology and Quality Control, National Nutrition Program, 2012, http://www.dftqc.gov.np/uploads/files/FoodCompositiontable.pdf.

[17] T. Longvah, R. Ananthan, K. Bhaskarachary, and K. Venkaiah, Indian Food Composition Tables, 2017, http://www.indiaenvironmentportal.org.in/files/file/IFCT2017Book.pdf.

[18] C. Pafumi, G. Zizza, M. Farina et al., "Comparison of dexa and ultrasonometry in the measurement of bone density," Archives of Gynecology and Obstetrics, vol. 266, no. 3, pp. 152-153, 2002.

[19] K. Chin and S. Ima-Nirwana, "Calcaneal quantitative ultrasound as a determinant of bone health status: what properties of bone does it reflect?" International Journal of Medical Sciences, vol. 10, no. 12, pp. 1778-1783, 2013.

[20] A. Gemalmaz, G. Dişcigil, and C. Ceylan, "Diagnostic performance of QUS for identifying osteoporosis in postmenopausal Turkish women," Turkish Journal of Medical Sciences, vol. 37, no. 5, pp. 303-309, 2007.

[21] S. R. Eis and E. M. Lewiecki, "Peripheral bone densitometry: clinical applications," Arquivos Brasileiros de Endocrinologia \& Metabologia, vol. 50, no. 4, pp. 596-602, 2006.

[22] L. Mazocco and P. Chagas, "Association between body mass index and osteoporosis in women from northwestern Rio Grande do Sul," Revista Brasileira de Reumatologia, vol. 57, no. 4, pp. 299-305, 2017.

[23] V. Prabha and A. Stanly, "Effect of body mass index on bone mineral density," International Journal of Community Medicine and Public Health, vol. 2, no. 4, pp. 380-383, 2015.

[24] T. Holmberg, M. Bech, T. Curtis, K. Juel, M. Grønbæk, and K. Brixen, "Association between passive smoking in adulthood and phalangeal bone mineral density: results from the KRAM study-the Danish Health Examination Survey 20072008," Osteoporosis International, vol. 22, no. 12, pp. 2989-2999, 2011.

[25] S. Quan, J. Jeong, and D. Kim, "The relationship between smoking, socioeconomic status and grip strength among community-dwelling elderly men in Korea: hallym aging study," Epidemiology and Health, vol. 35, Article ID e2013001, 2013.

[26] K. Ringle, "An investigation of bone mineral density and bone mineral content among hispanic women by lifestyle factors," 2009, https://kb.osu.edu/bitstream/handle/1811/37038/ bmd_and_bmc_in_hispanic_women_by_lifestyle_factors .pdf? sequence $=1$.

[27] J. J. Lee, R. Patel, J. S. Biermann, and P. J. Dougherty, "The musculoskeletal effects of cigarette smoking," The Journal of Bone and Joint Surgery-American Volume, vol. 95, no. 9, pp. 850859, 2013.

[28] K. M. Berg, H. V. Kunins, J. L. Jackson et al., "Association between alcohol consumption and both osteoporotic fracture and bone density," American Journal of Medicine, vol. 121, no. 5, pp. 406-418, 2008.

[29] E. Digitale, C. Hathaway, and K. C. S. Heneman, Calcium and Osteoporosis, Division of Agriculture and Natural Resources (ANR Publication 8138), University of California, 2008, http://anrcatalog.ucdavis.edu.

[30] A. Nordström, T. Tervo, and M. Högström, "The effect of physical activity on bone accrual, osteoporosis and fracture prevention," The Open Bone Journal, vol. 3, no. 1, pp. 11-21, 2011.

[31] J. Chubak, C. M. Ulrich, S. S. Tworoger et al., "Effect of exercise on bone mineral density and lean mass in postmenopausal women," Medicine \& Science in Sports \& Exercise, vol. 38, no. 7, pp. 1236-1244, 2006.

[32] N. Paker, M. Erbil, Z. S. D. Otlu, and E. Uysal, "Bone mineral density in healthy turkish women," Journal für Mineralstoffwechsel \& Muskuloskelettale Erkrankungen, vol. 12, no. 3, pp. 73-76, 2005.

[33] A. Devine, J. M. Hodgson, I. M. Dick, and R. L. Prince, “Tea drinking is associated with benefits on bone density in older women," American Journal of Clinical Nutrition, vol. 86, no. 4, pp. 1243-1247, 2007.

[34] H. Hallström, Coffee consumption in relation to osteoporosis and fractures observational studies in men and women [Doctoral thesis], Uppsala University, Uppsala, Sweden, 2013.

[35] C. L. Shen, J. K. Yeh, J. J. Cao, and J. S. Wang, "Green tea and bone metabolism," Nutrition Research, vol. 29, no. 7, pp. 437456, 2009.

[36] C. Harinarayan and T. Ramalakshmi, "Patterns of dietary calcium intake in south Indian rural, urban and metropolitan city subjects," Journal of Clinical and Scientific Research, vol. 4, no. 2, pp. 143-148, 2015.

[37] Y. H. D. Lee, Y. W. Lim, P. S. Ling, Y. Tan, M. Cheong, and K. S. Lam, "Inadequate dietary calcium intake in elderly patients with hip fractures," Singapore Medical Journal, vol. 48, no. 12, p. 1117, 2007.

[38] E. Tajik, Z. M. Shariff, A. J. Esfehani, C. Y. Mun, and F. Ebrahimi, "Dietary calcium intake and socioeconomic status are associated with bone mineral density in postmenopausal women," World Applied Sciences Journal, vol. 31, no. 2, pp. 244$52,2014$.

[39] E. A. de Jonge, J. C. Kiefte-de Jong, N. Campos-Obando et al., "Dietary vitamin A intake and bone health in the elderly: the Rotterdam Study," European Journal of Clinical Nutrition, vol. 69, no. 12, pp. 1360-1368, 2015. 


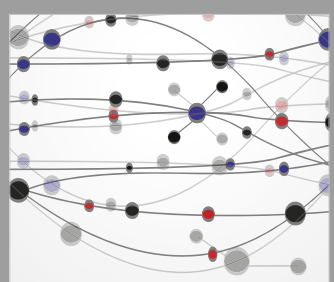

The Scientific World Journal
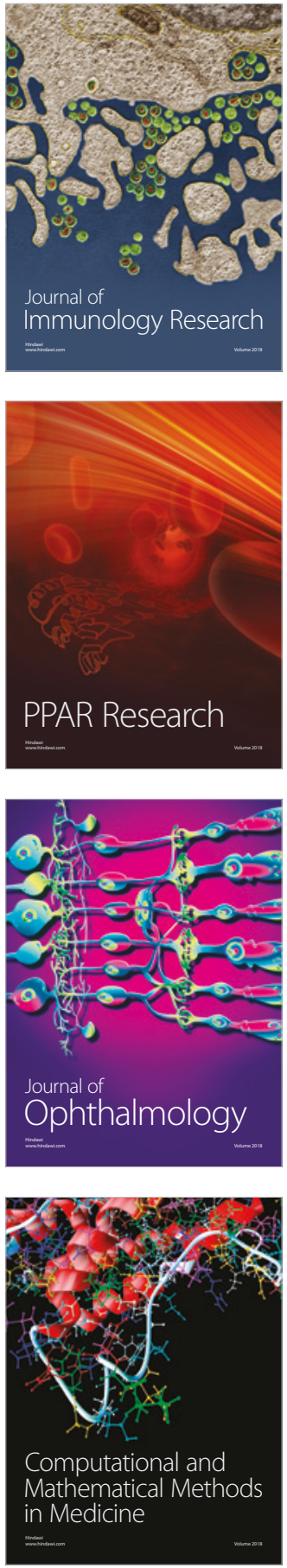

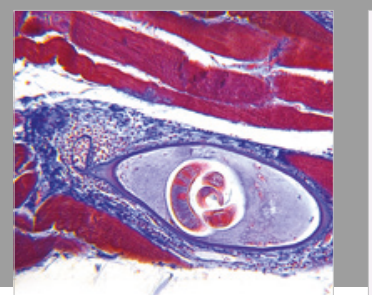

Gastroenterology Research and Practice

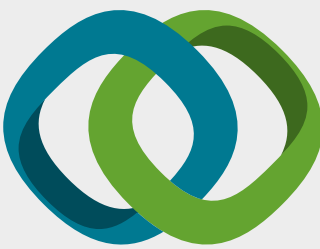

\section{Hindawi}

Submit your manuscripts at

www.hindawi.com
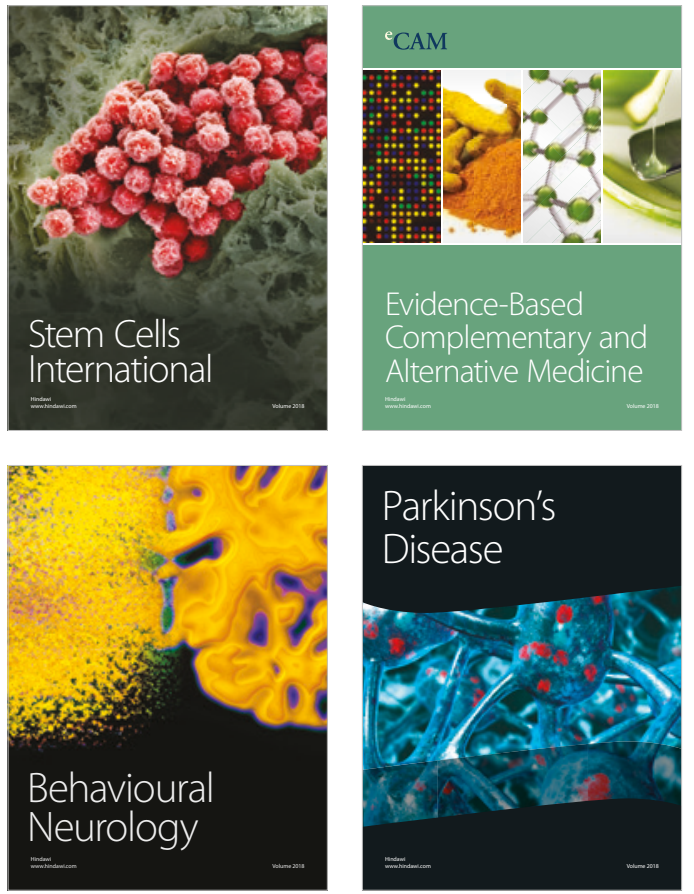

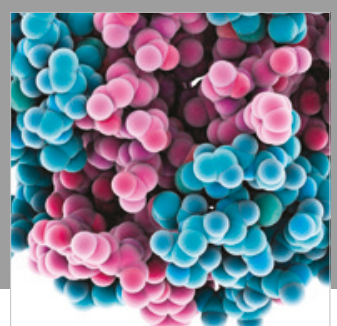

ournal of

Diabetes Research

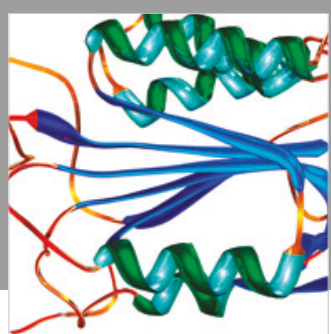

Disease Markers
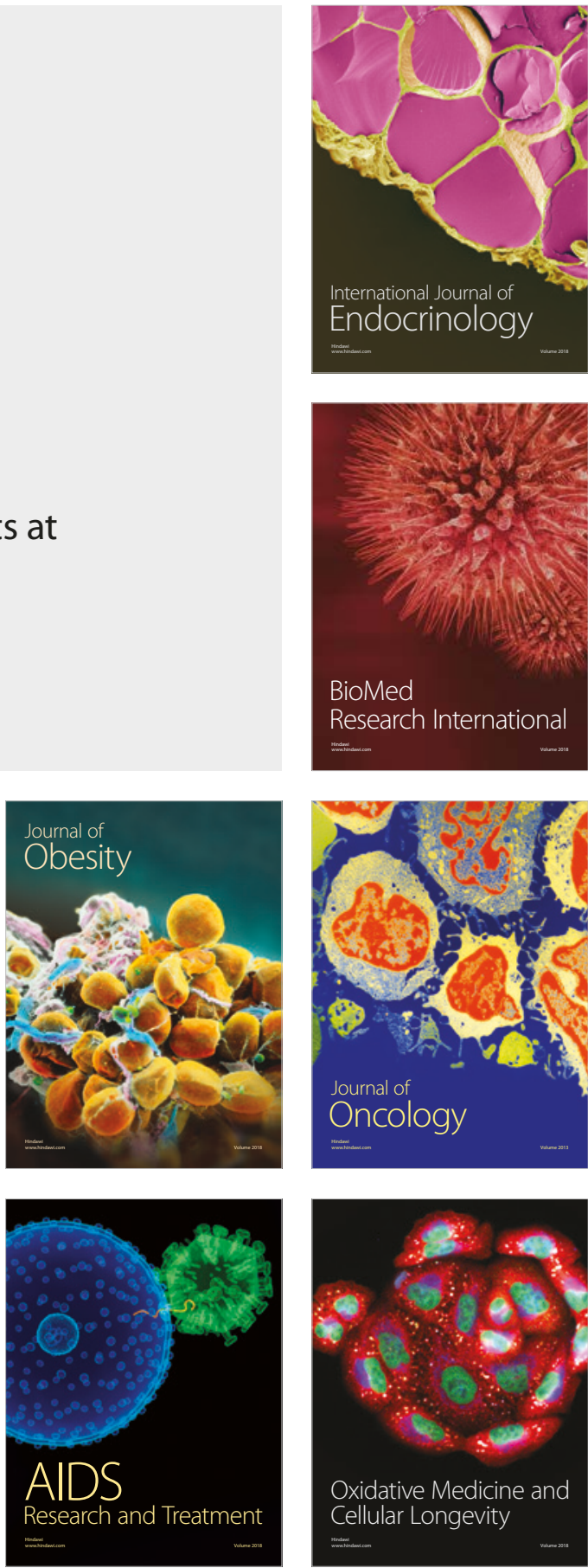